involved in the baseline surveys for the study. MH and KA participated in the diagnosis of dementia. MPL and TH participated in analysing the data and writing the paper. All the authors took part in planning the study and interpreting the data and commented on the manuscript. MK is the guarantor.

Funding: Academy of Finland grants 37573 and 63645 and EVO grant 477268.

Competing interests: None declared.

1 Skoog I, Lernfelt B, Landahl S, Palmertz B, Andreasson L-A, Nilsson L, et al. 15-year longitudinal study of blood pressure and dementia. Lance 1996:347:1141-5.

2 Launer LJ, Ross GW, Petrovitch H, Masaki K, Foley D, White LR, et al Midlife blood pressure and dementia: the Honolulu-Asia aging study. Neurobiol Aging 2000;21:49-55.

3 Notkola I-L, Sulkava R, Pekkanen J, Erkinjuntti T, Ehnholm C, Kivinen P, et al. Serum total cholesterol, apolipoprotein E4, and Alzheimer's disease. Neuroepidemiology 1998:17:14-20.

4 Braak E, Griffing K, Arai K, Bohl J, Bratzke H, Braak H. Neuropathology of Alzheimer's disease: what is new since A. Alzheimer? Eur Arch Psychiatry Clin Neurosci 1999;249(suppl 3):14-22.

5 Vartiainen E, Puska P, Jousilahti P, Korhonen HJ, Tuomilehto J, Nissinen A. Twenty-year trends in coronary risk factors in North-Karelia and in other areas of Finland. Int J Epidemiol 1994;23:495-504.

6 American Psychiatric Association. Diagnostic and statistical manual of mental disorders. 4th ed. Washington DC: American Psychiatric Association, 1994.

7 McKhann G, Drachman D, Folstein M, Katzman R, Price D, Stadlan EM. Clinical diagnosis of Alzheimer's disease: report of the NINCDS-ADRDA work group under the auspices of Department of Health and Human Services Task Force on Alzheimer's Disease. Neurology 1984;34:939-44

8 Hachinski VC, Iliff LD, Zilhka E, Du Boulay GH, McAllister VL, Marshall J, et al. Cerebral blood flow in dementia. Arch Neurol 1975;32:632-7.

9 Klungel OF, Kaplan RC, Heckbert SR, Smith NL, Lamaitre RN, Longstreth WT Jr, et al. Control of blood pressure and risk of stroke among pharmacologically treated hypertensive patients. Stroke among phar $000 ; 31: 420-4$.

10 Applegate WB. Hypertension in elderly patients. Ann Intern Med 1989;110:901-15

11 Forette F, Seux M-L, Staessen JA, Thijs L, Birkenhäger WH, Babarskiene $\mathrm{M}-\mathrm{R}$, et al. Prevention of dementia in randomised double-blind placebocontrolled systolic hypertension in Europe (Syst-Eur) trial. Lancet 1998:352:1347-51

12 Hofman A, Ott A, Breteler MMB, Bots ML, Slooter AJ, van Harskamp F, et al. Atherosclerosis, apolipoprotein $\mathrm{E}$, and prevalence of dementia and Alzheimer's disease in the Rotterdam study. Lancet 1997;349:151-4

13 Skoog I, Kalaria RN, Breteler MMB. Vascular factors and Alzheimer disease. Alzheimer Dis Assoc Disord 1999;13(suppl 3):106-14.

14 Davignon J, Gregg RE, Sing CF. Apolipoprotein E polymorphism and atherosclerosis. Arteriosclerosis 1988;8:1-21.

15 Kosunen O, Soininen H, Paljärvi L, Heinonen O, Talasniemi S, Riekkinen PJ Sr. Diagnostic accuracy of Alzheimer's disease: a neuropathological study. Acta Neuropathol 1996;91:185-93

16 Launer LJ, Wind WA, Deeg DJH. Nonresponse pattern and bias in a community-based cross-sectional study of cognitive functioning among the elderly. Am J Epidemiol 1994;139:803-12.

17 Brookmeyer R, Gray S, Kawas C. Projections of Alzheimer's disease in the United States and the public health impact of delaying disease onset. $\mathrm{Am}$ J Public Health 1998;88:1337-49.

(Accepted 19 March 2001)

\title{
A cognitive behavioural intervention to reduce sexually transmitted infections among gay men: randomised trial
}

John Imrie, Judith M Stephenson, Frances M Cowan, Shamil Wanigaratne, Andrew J P Billington, Andrew J Copas, Lesley French, Patrick D French, Anne M Johnson for the Behavioural Intervention in Gay Men Project Study Group

\begin{abstract}
Objective To determine the effectiveness of a brief cognitive behavioural intervention in reducing the incidence of sexually transmitted infections among gay men.

Design Randomised controlled trial with 12 months' follow up.

Setting Sexual health clinic in London.

Participants 343 gay men with an acute sexually transmitted infection or who reported having had unprotected anal intercourse in the past year.

Main outcome measures Number of new sexually transmitted infections diagnosed during follow up and self reported incidence of unprotected anal intercourse.

Results 72\% (361/499) of men invited to enter the study did so. $90 \%(308 / 343)$ of participants returned at least one follow up questionnaire or re-attended the clinic and requested a check up for sexually transmitted infections during follow up. At baseline, $37 \%(63 / 172)$ of the intervention group and 30\% $(50 / 166)$ of the control group reported having had unprotected anal intercourse in the past month. At 12 months, the proportions were $27 \%(31 / 114)$ and $32 \%$ (39/124) respectively $(\mathrm{P}=0.56)$. However, $31 \%$ (38/123) of the intervention group and 21\% (35/168) of controls had had at least one new infection diagnosed at the clinic (adjusted odds ratio 1.66, 95\% confidence interval 1.00 to 2.74). Considering only
\end{abstract}

men who requested a check up for sexually transmitted infections, the proportion diagnosed with a new infection was $58 \%(53 / 91)$ for men in the intervention group and $43 \%$ (35/81) for men in the control group (adjusted odds ratio 1.84, 0.99 to 3.40). Using a regional database that includes information from 23 sexual health clinics in London, we determined that few participants had attended other sexual health clinics.

Conclusions This behavioural intervention was acceptable and feasible to deliver, but it did not reduce the risk of acquiring a new sexually transmitted infection among these gay men at high risk. Even carefully designed interventions should not be assumed to bring benefit. It is important to evaluate their effects in randomised trials with objective clinical end points.

\section{Introduction}

Each year in the United Kingdom about 1400 homosexual men are newly diagnosed as being infected with HIV; this figure has remained comparatively stable for a decade. ${ }^{1}$ Gay men attending sexual health clinics in London report engaging in significantly more high risk sexual behaviour than gay men surveyed in community settings. ${ }^{2}$ Effective behavioural interventions to reduce sexual risk taking and infection with HIV and other sexually transmitted diseases are clearly needed, ${ }^{3}$ and sexual health clinics are an appro-
Department of Sexually Transmitted Diseases, Royal Free and University College Medical School, London WC1E 6AU

John Imrie senior research fellow Judith M Stephenson senior lecturer in epidemiology Frances M Cowan senior lecturer in genitourinary medicine

Andrew J Copas lecturer in statistics Anne M Johnson professor of epidemiology continued over

BMJ 2001;322:1451-6

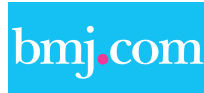

A description of the cognitive behavioural intervention appears on the BMJ's website 
Camden and

Islington

Community Health

Services NHS Trust,

London

WC1E 6AU

Shamil Wanigaratne

consultant clinical

psychologist

Andrew J P

Billington

genitourinary

medicine sexual

health coordinator

Lesley French

head of health

advising services

Patrick D French

consultant physician

Correspondence to:

J Imrie

jimrie@gum.ucl.ac.uk priate setting for such interventions. We developed a small group intervention aimed at gay men, which draws on several psychological models of behavioural change. $^{4-6}$ We evaluated its effects in a pragmatic randomised controlled trial using clinical end points (new sexually acquired infections) as well as self reported changes in behaviour.

\section{Participants and methods}

\section{Participants}

The study was approved by the University College London and University College London Hospitals ethics committee. From September 1995 to November 1997, we invited homosexual men attending a sexual health clinic in London to enter the trial if they presented with an acute sexually transmitted infection, reported having had unprotected anal intercourse with a partner of different HIV status in the past year, or expressed concern about their sexual practices. Men were only excluded if they were deemed by clinic staff to be unsuited for a group education and counselling intervention. Participants were randomly allocated using sealed opaque envelopes.

All participants received standard management consisting of a brief (20 minute) one to one counselling session about sexual risk behaviour; contact tracing was offered to those with a newly diagnosed infection; and participants could also be referred to clinic based or community based education on HIV prevention and counselling services. Additionally, participants assigned to the intervention were invited to a one day workshop. This had been shortened to one day because in a pilot study using an intervention spread across three occasions, too few men had attended all sessions. The intervention drew on the transtheoretical model of behavioural change 4 and the model of relapse prevention ${ }^{5}$; it also included elements of social learning theory and motivational interviewing. ${ }^{6}$ (A description of the cognitive behavioural intervention is available on the $B M / \mathrm{s}$ website.) Pairs of trained counsellors from the clinic facilitated the workshops. The quality of the intervention was assessed using participants' evaluations, reports from the facilitators' clinical supervisors, and focus groups. No payments were offered for attendance or follow up.

Behavioural outcomes were followed up using postal questionnaires. Clinic and laboratory databases were reviewed to identify new infections diagnosed at the clinic. Attendance at other clinics in greater London was determined by matching individuals to a regional database. Re-attendance at the clinic was not required by the protocol.

\section{Data analysis}

The sample size was calculated to detect a reduction of three fifths in the proportion of men acquiring a new sexually transmitted infection (from 20\%, as estimated from recent clinic data, to 8\%) in 12 months and a reduction of two fifths in the proportion reporting having unprotected anal intercourse in the past month (from $50 \%$ to $30 \%$ ). The aim was to recruit 346 men, assuming a statistical power of at least $80 \%$ and $25 \%$ loss to follow up.

Sexual behaviour outcomes were collected using questionnaires at baseline, 6 months, and 12 months.
Participants were asked about the number of sexual partners with whom they had had unprotected anal intercourse in the past month and the last year (at baseline and at 12 months) and the HIV status of those partners. We used two definitions of a new, sexually transmitted infection. The first was a broad definition including acute hepatitis B, syphilis, gonorrhoea, chlamydia, or non-specific urethritis, or the first clinical episode of herpes or genital warts. The second was a narrow definition that considered only acute bacterial infections (syphilis, chlamydia, or gonorrhoea); this was seen as a better proxy for unprotected anal intercourse. $^{7}$

Assessors who were blind to the participant's allocation reviewed the clinic's and the laboratory's databases to determine clinic attendance and diagnoses during follow up. To determine whether participants had attended other clinics during follow up, we matched their information to that on a regional database from 23 sexual health clinics in greater London using date of birth, sexual orientation, ethnic group, and postcode.

Screening for asymptomatic infection was not included in the original study protocol because we felt it would compromise recruitment. However, participants were more enthusiastic about the trial than expected. We therefore added an unlinked, anonymous urine analysis to detect undiagnosed infections the end of the trial. Specimens were returned by post and tested for Neisseria gonorrhoeae and Chlamydia trachomatis (LCx Probe, Abbott Laboratories, Chicago, IL).

Other outcomes assessed were psychological determinants of safer sex behaviours (such as self efficacy-for example, does the participant have confidence in his ability to use condoms properly) and uptake of other interventions in the clinic or community. Five psychometric measures were completed on the baseline questionnaire and each follow up questionnaire. These were the situational self confidence questionnaire, which measures self efficacy ${ }^{9}$; the Rosenberg self esteem questionnaire ${ }^{10}$; the readiness to change questionnaire, which identifies an individual's position relative to the model of stages of behavioural change ${ }^{411}$; the sexual risk cognition questionnaire, which measures beliefs associated with high risk sexual behaviour ${ }^{12}$; and the HIV related attitudes questionnaire. ${ }^{13}$ Scores on the situational self confidence questionnaire range from 0-10; higher scores suggest a higher level of self confidence. Scores on the Rosenberg questionnaire range from 10-40; lower scores suggest higher self esteem. Scores on the sexual risk cognition questionnaire range from $0-88$; lower scores suggest that a respondent has thought about sexual risk taking less frequently. Scores on the component scales of the HIV attitudes questionnaire range from $0-5$; higher scores suggest more positive attitudes towards taking control of one's risk of HIV.

Data from the questionnaires were double entered using EpiInfo software and analysed using SPSS and Stata software. The primary analysis included all participants who had been randomly allocated regardless of whether they had received the intervention (intention to treat analysis).

For clinical end points, we compared the cumulative proportion of men in each arm of the trial who had a new infection diagnosed at the clinic during fol- 
low up. For sexual behaviour outcomes, we compared the proportions reporting having had unprotected anal intercourse during the past month and the past year. For psychological measures, we analysed changes from baseline within the individual for each follow up questionnaire. For unadjusted comparisons between the arms of the trial we used the $\chi^{2}$ test for binary data and $t$ tests or Mann-Whitney $\mathrm{U}$ tests for continuous data. For binary outcomes, we adjusted for possible confounding factors at baseline using logistic regression. We also compared those who had attended the intervention with the controls (on-treatment analysis).

\section{Results}

Baseline characteristics, attendance, and follow up Altogether, 499 men were invited to enter the trial and $361(72 \%)$ agreed. Of these, 343 were randomly allocated ( 175 to the intervention group and 168 to the control) and 18, who had a long term partner in the trial, were assigned to the same arm as their boyfriend (11 in the intervention group and 7 in the control) (fig 1). The 18 men who had not been randomly allocated were excluded from the analysis.

Participants were similar to those who declined to participate in terms of age, occupational classification, and eligibility criteria but were more likely to be white $(\mathrm{P}=0.06)$ and have more education $(\mathrm{P}=0.04)$ (table 1$)$. At baseline, 2\% of participants (four from the intervention group and two from the control) were known to be HIV positive, and 59\% (201/343) (61\% (106/175) of the intervention group and $57 \%(95 / 168)$ of the control group) had tested negative for HIV in the past three months. The HIV status of the remaining 40\% (136/343) was considered to be unknown.

Of the 175 men allocated to the intervention, 124 $(71 \%)$ attended. Compared with non-attenders, they were more likely to have attended a workshop before (20\% $(22 / 108)$ v $3 \%(1 / 40), \mathrm{P}=0.01)$ and more likely to complete the questionnaire at 12 months $(77 \%(95 / 124)$ $v 41 \%(21 / 51), \mathrm{P}<0.001)$ (data not shown). Altogether $80 \%(276 / 343)$ of participants returned a questionnaire at 6 months and $71 \%(244 / 343)$ did at 12 months. Those completing the 12 month questionnaire were older (median (range) age 30 (18-51) years $v 27$ (18-58) years, $\mathrm{P}<0.001)$. Follow up data from one or both questionnaires or from clinic and laboratory databases were available for $90 \%$ (308/343) of participants.

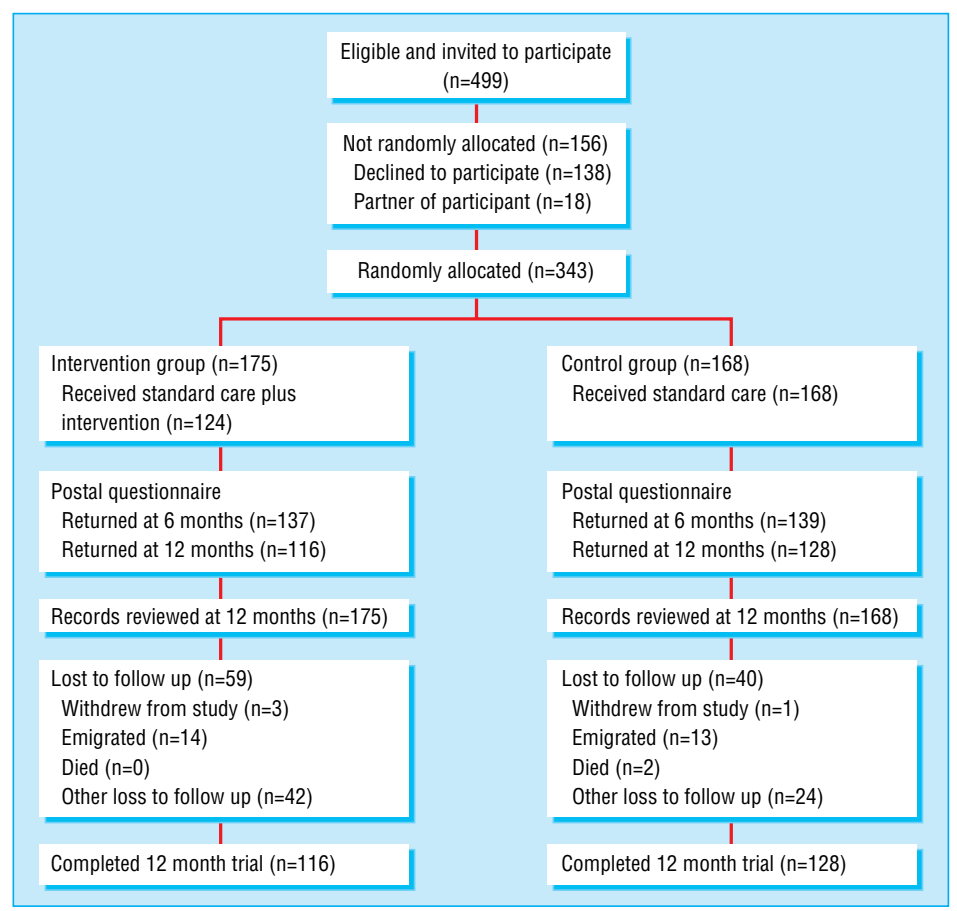

Progress of participants through the trial

\section{Impact of the intervention}

Self reported changes in sexual behaviour were modest but generally there was more improvement in the intervention group (table 2): in this group the proportion of men engaging in unprotected anal intercourse in the past month decreased from $37 \%$ $(63 / 172)$ at baseline to $24 \%(32 / 136)$ at 6 months and $27 \%(31 / 114)$ at 12 months. In the control group the proportion changed little: from $30 \%(50 / 166)$ at baseline to $32 \%(44 / 139)$ at 6 months and $32 \%(39 / 124)$ at 12 months. After adjusting for infections and unprotected anal intercourse at baseline, differences in these proportions between the arms of the trial were not significant $(P=0.07$ at 6 months and $P=0.31$ at 12 months). Findings were similar for the proportions having unprotected anal intercourse in the past 12 months $(61 \%(106 / 174)$ in the intervention group and $63 \%(104 / 166)$ in the control group at baseline compared with 50\% (58/116) and 59\% (76/128) respectively at 12 months). Of those who reported at baseline that they had had unprotected anal intercourse in the past month, $63 \%(39 / 62)$ of the interven-

Table 1 Sociodemographic characteristics of men invited to participate. Values are numbers (percentages) unless otherwise indicated

\begin{tabular}{|c|c|c|c|c|}
\hline & $\begin{array}{l}\text { All randomly allocated } \\
\text { participants }(n=343)\end{array}$ & $\begin{array}{l}\text { Intervention group } \\
(\mathrm{n}=175)\end{array}$ & $\begin{array}{c}\text { Control group } \\
(n=168)\end{array}$ & $\begin{array}{l}\text { Declined to participate } \\
\qquad(\mathrm{n}=138)\end{array}$ \\
\hline Median (range) age (years) & $29(18-58)$ & $29(18-49)$ & $29(18-58)$ & $28(17-59)$ \\
\hline \multicolumn{5}{|l|}{ Ethnicity: } \\
\hline White & $311(91)$ & $160(91)$ & $151(90)$ & $116^{*}(84)$ \\
\hline \multicolumn{5}{|l|}{ Education: } \\
\hline Beyond secondary school & $294(86)$ & $150(86)$ & $144(86)$ & $106 \dagger(77)$ \\
\hline \multicolumn{5}{|l|}{ Occupation: } \\
\hline Skilled non-manual & $195(57)$ & $91(52)$ & $104(62)$ & $76(55)$ \\
\hline Sexually transmitted infection at recruitment & $172(50)$ & $92(53)$ & $79(47)$ & $59(43)$ \\
\hline HIV workshop attended previously & $59(17)$ & $27(15)$ & $31(19)$ & NA \\
\hline
\end{tabular}

$\mathrm{NA}=$ not available.

${ }^{*} \mathrm{P}=0.06$ compared with all randomly allocated participants.

$\dagger P=0.04$ compared with all randomly allocated participants. 
tion group and $68 \%(34 / 50)$ of the control group reported that the last episode was with a partner of unknown or different HIV status. These proportions were $44 \%(14 / 32)$ and $65 \%(28 / 43)$, respectively, at 6 months $(\mathrm{P}=0.11)$ and $48 \%(15 / 31)$ and $46 \%(18 / 39)$ at 12 months $(\mathrm{P}=0.9)$.

A larger proportion of the intervention group had had a new sexually transmitted infection diagnosed during follow up (table 3). Around half of all men (53\% $(91 / 172)$ in the intervention group and 48\% (81/168) of the control) returned to the clinic during follow up and requested a check up for sexually transmitted infections. Restricting the analysis to this subgroup had little effect on the adjusted odds ratio (1.84, 95\% confidence interval 0.99 to 3.40 for the broad definition of infection and $1.84,0.82$ to 4.16 for the narrow definition). More men in the intervention group had a check up, and a higher proportion of them had a new infection than the control group (58\% (53/91) v 43\% $(35 / 81)$ for the broad definition and 23\% (21/91) $v$ $14 \%(11 / 81)$ for the narrow definition) (data not shown). Findings did not differ appreciably when the 18 men who had not been randomly assigned were included (data not shown).

We also analysed the data by site of infection to see whether new infections were likely to reflect high risk sexual behaviour (for example, rectal infections). Although the numbers were small, the incidence of rectal gonorrhoea was non-significantly higher $(\mathrm{P}=0.26)$ in the intervention group (9 cases) than the control group (4 cases) (data not shown). In the on-treatment analysis the risk of acquiring a new infection was similar to the that in the intention to treat analysis (broad definition 31\% (38/123) v 21\% (35/168); adjusted odds ratio for presenting with an acute infection at baseline 1.69 (95\% confidence inter- val 0.98 to 2.90 ) and for the narrow definition $11 \%$ $(14 / 123)$ v 7\% (11/168) respectively; adjusted odds ratio 1.65 ( 0.71 to 3.84$)$ ) (data not shown).

The higher rate of new infections among participants in the intervention arm was unexpected. We therefore extended the review of the clinic's and laboratory's databases to beyond 12 months to see if the adverse effect persisted. An intention to treat analysis showed that the difference between the arms of the trial in the risk of new infection attenuated over time. At a median follow up of 22 months (range 18-36 months) for the broad definition the adjusted odds ratio was $0.96(95 \%$ confidence interval 0.56 to 1.65$)$ and for the narrow definition 1.30 (0.53 to 3.19) (data not shown).

We were able to match $56 \%$ of participants (98 in the intervention group and 93 controls) to the regional database of sexual health clinics. Four men in each arm were matched to an attendance at another clinic, and only one attendance resulted in the diagnosis of an infection. Uptake of other counselling or prevention services was comparatively low and was not significantly different between the trial arms (table 3).

For the survey of urine samples we received specimens from 52\% (180) of the original 343 participants. Only one specimen from a member of the control group tested positive for $N$ gonorrhoeae; four tested positive for $C$ trachomatis (1 from the intervention group and 3 from the control).

Median scores for psychometric measures at baseline were similar in both arms (table 4). At the beginning of the study a high proportion of men were either in the "contemplation" stage (that is, considering adopting safer sex behaviour) or the "action" stage (that is, trying to practise safer sex) according to the transtheoretical model and the readiness to change

Table 2 Self reported changes in sexual behaviour. Values are number (percentage) of participants

\begin{tabular}{|c|c|c|c|c|c|c|c|c|}
\hline & \multicolumn{2}{|c|}{ Baseline } & \multicolumn{3}{|c|}{6 months } & \multicolumn{3}{|c|}{12 months } \\
\hline & $\begin{array}{l}\text { Intervention } \\
\quad(n=175)\end{array}$ & $\begin{array}{l}\text { Control } \\
(n=168)\end{array}$ & $\begin{array}{l}\text { Intervention } \\
(\mathrm{n}=137)\end{array}$ & $\begin{array}{l}\text { Control } \\
(n=139)\end{array}$ & P value* & $\begin{array}{l}\text { Intervention } \\
\quad(n=116)\end{array}$ & $\begin{array}{l}\text { Control } \\
(n=128)\end{array}$ & $P$ value* \\
\hline $\begin{array}{l}\text { Unprotected anal intercourse in the } \\
\text { past year }\end{array}$ & $106 / 174$ (61) & $104 / 166$ (63) & NA & NA & NA & $58 / 116(50)$ & $76 / 128$ (59) & 0.28 \\
\hline $\begin{array}{l}\text { Unprotected anal intercourse in the } \\
\text { past month: }\end{array}$ & $63 / 172(37)$ & $50 / 166(30)$ & $32 / 136(24)$ & 44/139 (32) & 0.07 & $31 / 114(27)$ & $39 / 124(32)$ & 0.31 \\
\hline $\begin{array}{l}\text { Last episode with partner of } \\
\text { different or unknown HIV status }\end{array}$ & $39 / 62(63)$ & $34 / 50(68)$ & $14 / 32(44)$ & $28 / 43(65)$ & 0.06 & $15 / 31(48)$ & $18 / 39(46)$ & 0.78 \\
\hline
\end{tabular}

NA=Not applicable.

${ }^{*} \mathrm{P}$ value for intervention group $v$ control after adjusting for sexually transmitted infections at baseline and whether the behaviour was reported at baseline.

Table 3 Number (percentage) of participants with new sexually transmitted infection diagnosed at the clinic or who attended other prevention services during 12 months of follow up

\begin{tabular}{|c|c|c|c|c|}
\hline & \multicolumn{2}{|c|}{ Group } & \multirow[b]{2}{*}{ Odds ratio $(95 \% \mathrm{Cl})$} & \multirow{2}{*}{$\begin{array}{l}\text { Adjusted odds ratio* } \\
\qquad(95 \% \mathrm{CI})\end{array}$} \\
\hline & Intervention ( $\mathrm{n}=175)$ & Control $(n=168)$ & & \\
\hline \multicolumn{5}{|l|}{ New sexually transmitted infection diagnosed: } \\
\hline All new infections diagnosed $†$ & $53 / 172(31)$ & $35 / 168(21)$ & 1.69 (1.03 to 2.77$)$ & 1.66 (1.00 to 2.74$)$ \\
\hline New bacterial infections diagnosed $\neq$ & $21 / 172(12)$ & $11 / 168(7)$ & $1.98(0.93$ to 4.26$)$ & 1.84 (0.85 to 3.99$)$ \\
\hline \multicolumn{5}{|c|}{ Use of other clinic or community prevention services: } \\
\hline Clinic based prevention service & $7 / 110(6)$ & $8 / 128(6)$ & $1.02(0.32$ to 3.23$)$ & $1.04(0.36$ to 2.98$)$ \\
\hline Community based prevention service & 14/107 (13) & $10 / 123(8)$ & 1.70 (0.67 to 4.35$)$ & 1.75 (0.74 to 4.12$)$ \\
\hline One to one counselling at a clinic & 18/112 (16) & 17/127 (13) & 1.24 (0.57 to 2.69$)$ & 1.20 (0.57 to 2.48$)$ \\
\hline One to one counselling in the community & $10 / 113(9)$ & $5 / 128(4)$ & 2.39 (0.72 to 8.32$)$ & $2.46(0.81$ to 7.46$)$ \\
\hline Contacted helpline & $16 / 113(14)$ & 18/127 (14) & $1.00(0.45$ to 2.19$)$ & $1.02(0.48$ to 2.17$)$ \\
\hline
\end{tabular}

*Odds ratio adjusted for presenting with acute infection at recruitment.

†Broad definition of new sexually transmitted infections included hepatitis B, first episodes of herpes or genital warts, syphilis, gonorrhoea, chlamydia, and non-specific urethritis.

‡Narrow definition of sexually transmitted infections included only common bacterial infections, specifically syphilis, chlamydia, and gonorrhoea. 
Table 4 Scores on psychometric measures at baseline and follow up*

\begin{tabular}{|c|c|c|c|c|}
\hline \multirow[b]{2}{*}{ Questionnaire } & \multicolumn{2}{|c|}{ Median (range) score at baseline } & \multicolumn{2}{|c|}{$\begin{array}{l}\text { Difference in change in mean score between intervention and } \\
\text { control groups }(95 \% \mathrm{Cl}) \dagger\end{array}$} \\
\hline & Intervention $(n=175)$ & Control $(n=168$ & 6 months & 12 months \\
\hline Sexual risk cognition ${ }^{12}$ & $12(0-72)$ & $11(0-55)$ & $-1.15(-3.80$ to 1.49$)$ & 0.645 (-2.70 to 3.99$)$ \\
\hline Situational self confidence $^{9}$ & $8.0(0.8-10)$ & $8.0(1.2-10)$ & $0.25(-0.08$ to 0.58$)$ & $0.02(-0.35$ to 0.39$)$ \\
\hline Rosenberg self esteem ${ }^{10}$ & $19(10-33)$ & $18(10-34)$ & $-1.10(-2.57$ to 0.37$)$ & $-0.22(-1.33$ to 0.89$)$ \\
\hline \multicolumn{5}{|l|}{ HIV attitudes questionnaire ${ }^{13}$ : } \\
\hline Self efficacy & $4.5(2.0-5.0)$ & $4.75(2.25-5.0)$ & 0.17 (0.02 to 0.32$)$ & $0.12(-0.05$ to 0.29$)$ \\
\hline Social norms & $4.33(2.33-5.0)$ & $4.67(2.33-5.0)$ & $0.03(-0.17$ to 0.23$)$ & $0.02(-0.19$ to 0.24$)$ \\
\hline Communication skills & $4.0(1.0-5.0)$ & $4.0(1.67-5.0)$ & $0.17(-0.02$ to 0.36$)$ & $0.23(0.02$ to 0.45$)$ \\
\hline Self labelling & $3.33(1.0-5.0)$ & $3.33(1.3-5.0)$ & 0.25 (0.00 to 0.49$)$ & $0.19(-0.09$ to 0.48$)$ \\
\hline Safer sex efficacy & $4.0(1.5-5.0)$ & $4.0(2.5-5.0)$ & $0.08(-0.11$ to 0.26$)$ & 0.25 (0.03 to 0.47$)$ \\
\hline Interpersonal barriers & $4.0(2.0-5.0)$ & $4.0(2.0-5.0)$ & 0.25 (0.06 to 0.45$)$ & $0.28(0.07$ to 0.49$)$ \\
\hline
\end{tabular}

*Explanation of scores given in the methods section.

†Mean within individual change from baseline. Intervention score minus control score.

Table 5 Number (percentage) of participants at each stage of the readiness to change scale ${ }^{11}$

\begin{tabular}{|c|c|c|c|c|c|c|c|c|}
\hline \multirow[b]{2}{*}{$\begin{array}{l}\text { Stage of readiness to } \\
\text { change }^{*}\end{array}$} & \multicolumn{2}{|c|}{ Baseline } & \multicolumn{3}{|c|}{6 months } & \multicolumn{3}{|c|}{12 months } \\
\hline & $\begin{array}{c}\text { Intervention } \\
(n=167)\end{array}$ & $\begin{array}{l}\text { Control } \\
(n=161)\end{array}$ & $\begin{array}{c}\text { Intervention } \\
(\mathrm{n}=127)\end{array}$ & $\begin{array}{l}\text { Control } \\
(n=126)\end{array}$ & $P$ value† & $\begin{array}{c}\text { Intervention } \\
(n=104)\end{array}$ & $\begin{array}{l}\text { Control } \\
(n=118)\end{array}$ & P value* \\
\hline Pre-contemplation & $6(4)$ & $3(2)$ & $6(5)$ & $10(8)$ & & $8(8)$ & $10(9)$ & \\
\hline Contemplation & $63(38)$ & $60(37)$ & $28(22)$ & $44(35)$ & 0.03 & $24(23)$ & $34(29)$ & 0.16 \\
\hline Action & $98(59)$ & 98 (61) & $93(73)$ & $72(57)$ & & $72(69)$ & $74(63)$ & \\
\hline
\end{tabular}

${ }^{\star}$ Explanation of stages given in the text.

$+\chi^{2}$ test for linear association comparing within individual changes from baseline.

scale (table 5). At 6 months, men in the intervention group had made significantly more progress in their scores on the readiness to change scales.

\section{Discussion}

There have been comparatively few randomised trials of interventions aimed at changing sexual behaviour to prevent the transmission of HIV and other sexually transmitted infections. ${ }^{14}$ Even fewer trials have used the incidence of infection as an end point together with reported sexual behaviour. This is the first such trial in a population of gay men to measure both clinical and behavioural outcomes. ${ }^{3}{ }^{1516}$ Analysis of the self reported behavioural outcomes suggested a weak beneficial effect, but analysis of the clinical end points indicated that the intervention was more likely to be harmful, although this was of borderline significance. However, the link between sexual behaviour and sexually transmitted infection is not simple. ${ }^{717-19}$ Some infections, such as gonorrhoea, are usually acquired through penetrative sex, but others, such as herpes, can be acquired through low risk, non-penetrative sex. Furthermore, new viral infections can be hard to distinguish clinically from recurrent episodes. Thus, a broad definition of new infections may include some that were not acquired through high risk sex or that preceded the intervention, whereas a narrow definition may miss infections that were acquired through high risk sex. We tried to avoid this problem by using two definitions. When it is not possible to mask a participant's allocation, as in this study, it is particularly important to include clinical end points and not rely solely on self reported behavioural outcomes because these tend to overestimate benefit. ${ }^{30}$

The higher risk of acquiring a sexually transmitted infection among participants in the intervention arm was unexpected, at odds with the data on sexual behaviour, and clearly a cause for concern. However, similar findings have been reported in other trials of behavioural interventions that used the clinical diagnosis of an infection as an end point. ${ }^{3}$ Three observations suggest that the increased risk of infection in our study is unlikely to be explained adequately by bias in the ascertainment of infection: screening rates at the clinic were similar in the two arms of the trial, and the proportion of men with a new infection was higher in the intervention group; matching using the regional database showed that we were unlikely to have missed many infections diagnosed elsewhere; and despite a comparatively low response rate, screening of urine samples suggested that the prevalence of asymptomatic infection in this population was low. Alternative explanations for the discrepancy between behavioural and clinical outcomes include bias due to loss to follow up or desirability bias, whereby participants in the intervention may have wished or felt obliged to report safer sexual behaviours. ${ }^{17} 2021$

The attenuation of differences between the two arms of the trial in the risk of becoming infected over time (as suggested by the extended review of the databases) supports the conclusion that the intervention may have led to an increased, albeit transient, risk of acquiring a new infection. Another possible explanation is that the intervention engendered in the participants a misplaced sense of confidence in their ability to negotiate high risk sexual situations, but this was not borne out by changes in the appropriate psychometric measures (table 4). We also considered the possibility that other interventions may have affected the outcome of the trial, but the uptake of other HIV prevention and counselling services was comparatively low and similar between the two arms.

Despite its promise and acceptability, the brief cognitive intervention aimed at gay men at high risk of sexually transmitted infection did not reduce their risk of acquiring new infections. Even carefully formulated 


\section{What is already known on this topic}

The need for effective HIV prevention strategies based on reducing sexual risk behaviour remains important

Few interventions to reduce sexual risk behaviour have been rigorously evaluated using randomised controlled trials

\section{What this study adds}

This is the first randomised controlled trial of an intervention addressing sexual behaviour in homosexual men that uses sexually transmitted infections and self reported behaviour as end points

The intervention was brief and feasible to use in a busy clinic, but it did not reduce the risk of participants acquiring new infections

The potential for behavioural interventions to do more harm than good needs to be taken seriously

behavioural interventions should not be assumed to bring benefit. It is important to evaluate their effects in randomised trials using clinical end points wherever possible.

Other members of the Behavioural Intervention in Gay Men Project Study Group are: Richard Barrett, Paul Bean, Rebecca Bickersteth, John Develin, Sandy Gale, Dr Sue Gessler, Debbie Holland, Angela McCadden, Kevin Miles, Nikki Penny, Ann Petruckevitch, Gillian Rhind, Kaye Stratton, and Dawn Whittaker. We thank all the study participants and the nurses, health advisers, doctors, and reception staff at the clinic who supported the study team. We owe particular thanks to the facilitators: Richard Barrett, Rebecca Bickersteth, Emma Callow, David Cornforth, Ruth Cracknell, Rebecca French, Jo Greenway, Mike Jones, Theresa Melrose, Kevin Miles, Simon Paragreen, Michael van Djikhuizen, and Simon Wright. We also thank Caroline Carder and Dr Geoffrey Ridgway, Clinical Microbiology Department, University College London Hospital; Dr Stephen Sutton, Imperial Cancer Research Fund Health Behaviour Unit, Royal Free and University College Medical School; Maria Griffin, Ali Judd, and Matthew Hickman of the Department of Social Science and Medicine, Imperial College School of Medicine, participating on behalf of the North Thames Genitourinary Medicine Clinical Directorate, London; and Dr John Parry and Julie Newham, Hepatitis and Retrovirus Laboratory, Central Public Health Laboratory, London.

Contributors: JI coordinated the study, participated in designing the questionnaires, coauthored the participants' workbook, and prepared the first draft of the paper.JMS was the principal investigator, designed the study, wrote the study proto$\mathrm{col}$, and contributed substantively to the paper. FMC had the idea for the study and advised on designing the questionnaire and recruiting participants. SW developed the intervention and the training programme for facilitators, selected the psychometric outcome measures, and provided clinical supervision to the facilitators. AJPB assisted in developing the intervention and the training programme for facilitators, coauthored the participants' workbook, and provided clinical supervision to the facilitators. AJC oversaw the collection of data and performed the statistical analyses. LF managed the team of facilitators and advised on the content and delivery of the intervention. PDF advised on recruitment strategies and delivering the intervention, and facilitated the team's work in the clinic. AMJ advised on the study design. All authors reviewed successive drafts of the paper. JI and JMS are guarantors for the study.

Funding: North Thames Regional Health Authority and the Camden and Islington Health Authority, London.

Competing interests: None declared.
1 Public Health Laboratory Service. AIDS/HIV quarterly surveillance tables. No.44:99/2; June 1999. http://www.phls.co.uk/facts/HIV/ hivquarterly.htm (accessed Sept 2000).

2 Dodds J, Nardone A, Mercey DE, Johnson AM. Increase in high risk sexual behaviour among homosexual men, London 1996-8: cross sectional, questionnaire study. BMJ 2000;320:1510-1.

3 Stephenson JM, Imrie J, Sutton SR. Rigorous trials of sexual behaviour interventions in STD/HIV prevention: what can we learn from them? AIDS 2000;14(suppl 3):S115-24.

4 Prochaska JO, DiClemente CC, Norcross JC. In search of how people change. Applications to addictive behaviors. Am Psychol 1992;47:1102-14.

5 Marlatt GA, Gordon JR. Relapse prevention: maintenance strategies in the treatment of addictive behaviors. New York: Guildford, 1985.

6 Bandura A. Social cognitive theory and exercise of control over HIV infection. In: DiClemente RJ, Peterson J, eds. Preventing AIDS: theories and methods of behavioural interventions. New York: Plenum, 1994.

7 Young H, Moyes A, McKenna JG, McMillan A. Rectal gonorrhoea and unsafe sex. Lancet 1991;337:853.

8 Hickman M, Griffin M, Judd A, Renton A. STI surveillance and commissioning information system (SCIS): report of pilot project including standard tables for GUM clinics in the former North Thames region for 1997 and 1998. London: Centre for Research on Drugs and Health Behaviour, Imperial College of Science, Technology, and Medicine, 1999.

9 Wanigaratne S, Billington A, Williams M. Initiating and maintaining safer sex: evaluation of group work with gay men. In: Catalan J, Sherr L Hedges B, eds. The impact of AIDS: psychological and social aspects of HIV infection. Singapore: Harwood Academic, 1997: 27-41.

10 Rosenberg M. Society and adolescent self image. Princeton, NJ: Princeton University, 1965

11 Rollnick S, Heather N, Gold R, Hall W. Development of a short "readiness to change" questionnaire for use in brief, opportunistic interventions among excessive drinkers. Br J Addict 1992;87:743-54.

12 Shah D, Thornton S, Burgess A. Sexual risk cognitions questionnaire: a reliability and validity study. AIDS Care 1997;4:471-80.

13 Hays R, Kegeles S, Coates TJ. High HIV risk-taking among young gay men. AIDS 1990;4:901-7.

14 Oakley A, Fullerton D, Holland J. Behavioural interventions for HIV/AIDS prevention. AIDS 1995;9:479-86.

15 Holland J, Arnold S, Fullerton D, Oakley A, Hart G. Review of effectiveness of health promotion interventions for men who have sex with men. London: Social Science Research Unit, Institute of Education,1994.

16 Kegeles SM, Hart GJ. Recent HIV-prevention interventions for gay men: individual, small-group and community-based studies. AIDS 1998;12(suppl A):S209-15.

17 Aral SO, Peterman TA. Do we know the effectiveness of behavioural interventions? Lancet 1998;351(suppl 3):33-6.

18 Peterman TA, Lin LS, Newman DR, Kamb ML, Bolan G, Zenilman J, et al. Does measured behavior reflect STD risk? An analysis of data from a randomized controlled behavioral intervention study. Sex Transm Dis 2000;27:446-51

19 Fishbein M, Jarvis B. Failure to find a behavioral surrogate for STD incidence-what does it really mean? Sex Transm Dis 2000;27:452-5.

20 Stephenson J, Imrie J. Why do we need randomised controlled trials to assess behavioural interventions? BMJ 1998:316:611-3.

21 Zenilman JM, Weisman CS, Rompalo AM, Ellish N, Upchurch DM, Hook EW 3rd, et al. Condom use to prevent incident STDs: the validity of selfreported condom use. Sex Transm Dis 1995;22:15-21

(Accepted 22 March 2001)

\section{Corrections and clarifications}

How policy informs the evidence

Editors are not immune to the dangers of abbreviations. In a letter by Arminée Kazanjian ("Comprehensive evidence is needed in decision making," 26 May, p 1304) we rather foolishly spelt out the author's abbreviation "CTs" as computed tomography (see beginning and end of third paragraph). In most situations this is indeed the usual meaning, but unfortunately in this case the author was referring to clinical trials. We apologise for this.

Efficacy and safety of rivastigmine in patients with Alzheimer's disease: international randomised controlled trial

We have recently been alerted to two small errors in a table in this paper by Michael Rösler and colleagues (1999;318:633-8). In the intention to treat analysis for high dose rivastigmine, the $\mathrm{P}$ value versus placebo for the Alzheimer's disease assessment scale (cognitive subscale) should be 0.011 $[$ not $<0.1]$ and for the progression deterioration scale should be 0.07 [not $<0.1]$. 